\section{Representações e experiências das mulheres sobre a assistência ao parto vaginal e cesárea em maternidades pública e privada}

\author{
Women's representations and experiences with \\ vaginal and cesarean delivery in public \\ and private maternity hospitals
}

\footnotetext{
${ }^{1}$ Faculdade de Serviço Social, Universidade do Estado do Rio de Janeiro, Rio de Janeiro, Brasil.

2 Escola Nacional de Saúde Pública Sergio Arouca, Fundação Oswaldo Cruz, Rio de Janeiro, Brasil.

3 Centro de Gestão e Estudos

Estratégicos, Brasília, Brasil.

4 Superintendência de

Atenção Básica, Educação em

Saúde e Gestão Participativa

Secretaria de Estado de

Saúde e Defesa Civil do Rio

de Janeiro, Rio de Janeiro,

Brasil.

5 Programa de Pós-graduação

em Saúde Pública,

Universidade Federal

de Santa Catarina,

Florianópolis, Brasil.

Correspondência

A. S Gama

Faculdade de Serviço Social,

Universidade do Estado do

Rio de Janeiro.

Rua Professor Gastão

Bahiana 399, apto. 103,

Rio de Janeiro, $R J$

22071-030, Brasil.

andreasgama@gmail.com
}

\section{Abstract}

This study analyzes the different representations and experiences of women from different social classes, including issues related to their relations with hospital staff in different institutional settings. This qualitative study focused on women who had experienced both types of delivery, in three maternity hospitals in Rio de Janeiro, Brazil (one public, one fully private, and another private under an outsourcing agreement with the public health system). The study showed that variations in public and private service models result in different types of delivery care and different relations with staff, and are reflected in different birthing experiences for the women. However, a critical gender perspective shows that in both cases, the service models reproduce the medicalization of childbirth and women's submission as objects in the birthing process. Although this is manifested in different ways in the three groups, the end result is to reduce the range of care and the possibility of women's empowerment during childbirth.

Maternal-Child Health Services; Natural Childbirth; Cesarean Section
Andréa de Sousa Gama ${ }^{1}$
Karen Mary Giffin ${ }^{2}$
Antonia Angulo-Tuesta ${ }^{3}$
Gisele Peixoto Barbosa ${ }^{4}$
Eleonora d'Orsi ${ }^{5}$

\section{Introdução}

Há três décadas, estudiosos e programadores de saúde vêm problematizando as condições da atenção à saúde reprodutiva no Brasil. Na assistência ao parto, uma das questões mais preocupantes é a sua crescente medicalização e "cirurgificação", tendo o país uma das mais altas taxas de cesárea do mundo $(38,6 \%) 1$.

A partir da segunda metade da década de 1990, verificamos uma série de iniciativas governamentais que objetivam a redução das altas taxas de cesárea e a qualificação do conjunto da assistência perinatal. As Portarias $n^{\circ} .2 .816$ de 29 de maio de 1998 e $n^{\circ} .466$ de 14 de junho de 2000 instituem um porcentual máximo de cesáreas no SUS, por hospital e para cada estado federativo, respectivamente; introduz-se o pagamento de analgesia para parto normal e recomenda-se a inserção da enfermagem obstétrica na assistência ao pré-natal e ao parto de baixo risco obstétrico ${ }^{2}$. Outras medidas são a criação do Prêmio Galba de Araújo para maternidades que atendam de modo humanizado os programas de capacitação de parteiras e doulas, a criação de centros de parto normal, a regulamentação da Lei de Planejamento Familiar que impacta na nociva associação "cesárea-laqueadura" e o Programa de Humanização do Pré-Natal e Nascimento.

Todas essas intervenções governamentais ilustram a preocupação e a disponibilidade das autoridades em redefinir e qualificar o modelo 
de assistência ao parto no Brasil. Entretanto, a evolução das taxas de cesárea no SUS, entre 1995 e 2005, mostra uma redução que vai de $31,97 \%$ para $24 \%$ nos primeiros cinco anos e o retorno de uma linha de crescimento entre 2000 e 2005 , chegando a $38,6 \%$ dos partos no SUS 1 . Se compararmos a proporção de nascidos vivos por cesárea, entre 1999 e 2004, verificamos o seu crescimento de $36,9 \%$ para $41,75 \%$ (Sistema de Informações sobre Nascidos Vivos. http://www.datasus.gov. br, acessado em 14/Nov/2007). Esses dados ilustram que, apesar dos esforços governamentais, seguindo o preconizado pela Organização Mundial da Saúde (OMS), as elevadas taxas de cesárea persistem e não sofrem impactos consideráveis. Do mesmo modo, levando em conta o conjunto da assistência em saúde no país, as taxas mostram importantes diferenças entre o setor público $(38,6 \%)$ e privado $(83,51 \%) 3$.

Nesse cenário, observamos que são poucos os estudos que dão visibilidade aos significados, experiências e necessidades das mulheres relativos ao parto e sua assistência, bem como suas demandas nesse processo de rediscussão do modelo de assistência ao parto. Quais os sentidos atribuídos ao parto normal e à cesárea? De que forma as relações de gênero na saúde influenciam essas percepções e a qualidade da atenção ao parto? De que maneira mulheres de diferentes segmentos de classe social vivenciam o processo de gestação e parto? Há variações que estão relacionadas com a prática médica e a organização dos serviços?

Neste estudo, tendo como eixo teórico a categoria gênero, analisamos as diferentes representações e experiências das mulheres quanto ao parto vaginal e cesárea, bem como investigamos a natureza das relações profissionais de saúde/ usuárias no contexto institucional em que estão inseridas, supondo que contribuem para a manutenção de altas taxas de cesárea e de outras intervenções no parto, nos diferentes modelos de organização dos serviços: público, conveniado com o SUS e privado.

\section{Relações de gênero e parto}

A construção social do feminino e do masculino tem forte peso no exame da condição social de homens e mulheres. O princípio feminista de que o "pessoal é político" contribuiu para o descortinamento da condição feminina, demonstrando que associadas à divisão social do trabalho e às desigualdades entre as classes, operam-se outras divisões como a divisão sexual do trabalho, do poder e do prazer, pelas quais caberia à mulher, ressaltando sua posição de classe, os trabalhos pior remunerados, o não ter fala e visibilidade, a não decisão (ou a limitação) sobre o seu corpo e sexualidade e a pressão de viver sob a égide de estereótipos bem definidos. As relações de gênero evidenciam hierarquias e subordinações, o que nos impulsiona a buscar entender como estas se reproduzem e se articulam com as iniqüidades em saúde.

A partir da década de setenta, o movimento de mulheres no Brasil busca reafirmar o direito à contracepção, na medida em que a maternidade era vista como uma imposição social que cristalizava o lugar da mulher no âmbito da reprodução. Passa-se também a reconhecer que as condições de assistência ao exercício reprodutivo se desenvolvem em situação de opressão, seja pelo fenômeno moderno da medicalização do corpo feminino, seja pelo não-reconhecimento dos direitos das mulheres de tomar decisões reprodutivas ${ }^{4}$. Esse movimento passa a questionar o modelo médico centrado na "patologização" da reprodução e da sexualidade, que suprime as reflexões sobre o parto como uma construção sociocultural condicionada aos aspectos de gênero e classe social 5 .

Entretanto, observa-se hoje que a quase totalidade das iniciativas relacionadas à saúde das mulheres tem se caracterizado por manipular seus corpos e suas vidas, visando a objetivos que não as reconhecem como sujeitos de sua saúde 4 . Talvez por isso, muitas iniciativas não tenham logrado sucesso na melhoria da saúde das mulheres porque insistem em expropriar a autodeterminação sobre seus corpos e suas vidas ${ }^{4}$. O uso abusivo da cesárea e a alta prevalência de mulheres esterilizadas ou usando métodos anticoncepcionais inadequados são exemplos dessas distorções 5 .

O parto é um ato cultural, pois reflete os valores sociais prevalentes historicamente em cada sociedade. Como o parto é regulado por regras sociais determinadas, se o compreendemos - bem como sua assistência - como "processo e produto" das relações de gênero 6 , vemos que esta assistência pode tratar de mulheres muito distintas, segundo suas representações corporais, inserção de classe social e características étnico-raciais e geracionais. Daí a importância de se verificar as representações e experiências atuais das mulheres quanto às formas de parturição e sua assistência em serviços de saúde diferenciados. 


\section{Metodologia}

A pesquisa foi desenvolvida em três maternidades do Município do Rio de Janeiro, Brasil, sendo uma pública, uma conveniada com o SUS e uma particular, no período compreendido entre março e setembro de 1999. Com a finalidade de comparar as experiências de parto, definimos como sujeitos da pesquisa mulheres que haviam passado pelos dois tipos de parto. Desenvolveu-se, então, o seguinte desenho de amostra com parturientes acima de 18 anos: 11 com partos vaginais pós-cesárea (PV pós-PC), sendo 8 nas maternidades pública e conveniada e 3 na maternidade privada, e 12 que tiveram cesáreas pós-vaginal (PC pós-PV), 8 nas maternidades pública e conveniada e 4 na maternidade privada. Foram realizadas entrevistas semi-estruturadas em profundidade, sendo 16 nas maternidades pública e conveniada com o SUS e 7 na maternidade particular.

As maternidades pública e conveniada com o SUS também compunham o campo empírico de uma pesquisa epidemiológica sobre os fatores associados à realização de cesáreas e foram escolhidas, respectivamente, pelo seu perfil de alto e baixo risco obstétrico.

Encontramos muitas dificuldades para a realização da pesquisa na maternidade privada. Vários fatores contribuíram para essa situação: o difícil acesso às mulheres em decorrência das restrições institucionais, na medida em que o contato se dava por meio da indicação e mediação do médico responsável pelo parto, mediante uma lista apresentada pela direção do hospital; o grande número de primíparas e a pouca variação em relação ao tipo de parto para as multíparas, sendo a cesárea absolutamente majoritária. Tal fato, além de sinalizar diferenças importantes, nos demandou vários meses de contatos pessoais e telefônicos com os médicos e, ao final, foram entrevistadas nessa maternidade sete mulheres com o perfil necessário para a pesquisa.

As entrevistas foram realizadas e gravadas nas maternidades, estando as puérperas com 24 a 72 horas de pós-parto. O tempo de duração variou entre uma hora e uma hora e cinqüenta minutos.

O estudo foi aprovado pelo Comitê de Ética em Pesquisa da Escola Nacional de Saúde Pública Sergio Arouca, Fundação Oswaldo Cruz, e em cumprimento à norma, todas as entrevistadas assinaram o Termo de Consentimento Livre e Esclarecido no qual estava assegurada a confidencialidade e o anonimato das informações prestadas.

\section{Resultados e discussão}

\section{Características sócio-econômicas e obstétricas}

A maioria das entrevistadas nas maternidades pública e conveniada com o SUS encontrava-se na faixa de 18 a 29 anos; tinha baixa escolaridade (ensino fundamental incompleto); baixo poder aquisitivo (60\% tinham renda per capita de até $\mathrm{R} \$ 150,00$, período em que o salário mínimo era de $\mathrm{R} \$ 136,00)$ e residia principalmente na Zona Oeste e Baixada Fluminense. A maioria das mulheres desse grupo não possuía trabalho remunerado (60\%), vínculo previdenciário (90\%) e entre aquelas que exerciam algum tipo de trabalho destacavam-se atividades informais, de pouca qualificação e baixa remuneração. Aproximadamente dois terços se autodeclararam pardas e negras e metade destas não residia com os companheiros.

Entre as informantes da maternidade privada, a maioria estava acima dos 30 anos, possuía um bom nível de escolaridade (ensino médio e superior completo); renda familiar entre $\mathrm{R} \$ 1.000,00 \mathrm{e}$ $\mathrm{R} \$ 1.500,00$ per capita e residiam nas Zonas Oeste (Barra da Tijuca) e Sul. Realizavam trabalhos remunerados em atividades formais, qualificadas e com melhor remuneração. Todas se autodeclararam brancas e casadas. As mulheres desse grupo tiveram seus partos pagos por planos privados de saúde.

Em relação a algumas características da história obstétrica, percebemos semelhanças na realização do pré-natal (100\% para os dois grupos), na paridade $(40 \%$ com dois filhos na maternidade pública e conveniada e $60 \%$ na maternidade privada) e pequenas diferenças na condição de risco obstétrico.

\section{Representações e experiências quanto ao parto normal e cesárea}

Na transição do status de mulher para o de mãe, o parto é um momento importante de construção da identidade de gênero feminina. O parto como um ritual transformativo apresenta uma ampla heterogeneidade social, segundo características culturais, religiosas, étnicas e de classe social 7. Nessa direção, identificamos que as circunstâncias e expectativas das mulheres são partes constitutivas da experiência do parto.

As mulheres entrevistadas foram estimuladas a comparar suas diferentes experiências de parto nas distintas modalidades de assistência à saúde. Ao compararem o parto normal e a cesárea, as puérperas de ambos os estratos sócio-econômicos destacaram maiores vantagens para o parto 
normal. São eles: o protagonismo da mulher, as diferenças no cuidado médico, a qualidade da relação com o bebê e a recuperação no pós-parto. As representações quanto ao parto normal são de um parto ativo, no qual as dores são vividas como as “dores de mãe". "É botar o neném pra fora. $E$ muito bonito". Sinalizaram, também, que o parto normal é mais saudável para o bebê e a mulher, por ser algo mais natural. Pode-se afirmar que a passagem do status de mulher para o de mãe, mediada pela cesariana, perderia parte de seu sentido, tendo em vista a anulação do protagonismo feminino no momento do parto.

"O parto atual porque participei do nascimento do meu filho. Eu senti o que é na verdade ter um filho, porque apesar de estar anestesiada, você sente perfeitamente o filho sair. Eu achei tão bonito que chorei na hora. Depois do parto já tava andando, falando, rindo. Na cesárea, tive uma crise de tosse que pensei que ia arrebentar tudo" (PV pós-PC; setor privado).

Investigamos também as vantagens e desvantagens da cesárea. Na primeira, constatamos a ausência das dores do trabalho de parto e a possibilidade da laqueadura. Como desvantagens foram mencionadas as dores no pós-parto, as dificuldades de recuperação e os riscos inerentes à cirurgia. Ressaltaram que a cesárea deve ser feita somente em caso de risco para a mãe ou o bebê.

Ao perguntar a opinião das entrevistadas sobre o aumento crescente de mulheres que fazem uma cesárea, a pedido ou não, o principal fator foi o medo das dores do parto e o desconhecimento das vantagens do parto normal. Algumas mulheres do setor privado destacaram a possibilidade de programar o parto devido à vida agitada da mulher contemporânea, em vez de esperar pela imprevisibilidade do parto normal.

"Porque aparentemente tudo é mais fácil na cesárea. Elas acham que não vão ter dor, marca-se o melhor dia e hora. No fundo a mulher acha que não tem capacidade de botar o filho no mundo e então se entrega nas mãos dos médicos. Você tem a impressão de uma coisa mais fácil, mas eu não acho mais fácil" (PV pós-PC; setor privado).

Contudo, algumas entrevistadas de ambos os grupos argumentaram que o principal motivo para o aumento de cesáreas encontra-se na conveniência do médico, porque é um parto mais rápido, na falta de paciência em esperar a progressão do parto normal ou mesmo devido à insegurança, caso o parto saia do padrão de evolução esperado.

Procuramos investigar a influência do grupo social quanto à preferência pelo parto normal ou cesárea, tomando a família e a rede de amizade como critério. Identificamos a influência materna e o fato de todas terem nascido de parto nor- mal como aspectos que contribuíram para essa preferência entre as mulheres do setor público. A influência das amigas das informantes do setor público em ambas as modalidades de parto também era eminentemente favorável ao parto normal, pelo protagonismo da mulher e pela melhor recuperação, apesar de destacarem a dor do parto como um aspecto desfavorável. Em geral, essas mulheres apresentaram uma visão negativa da cesariana e sentem-se estimuladas a terem partos normais pela preferência do seu grupo social.

Entre as informantes do setor privado, apesar de a maioria também ter nascido de parto normal, não acham que isto as influenciou no desejo de também tê-lo e atribuem a sua preferência ao parto normal porque são adeptas das "coisas naturais". No setor privado, as mulheres fazem mais cesáreas e mesmo com a pouca vivência no seu círculo social quanto ao parto normal, as entrevistadas destacaram que isto não as influenciou. Percebe-se que há dois movimentos nesse grupo social, o das mulheres que rechaçam a possibilidade do parto normal e o daquelas que se sentiram frustradas por não o terem realizado: " $E u$ tenho uma amiga que falava que eu era louca em querer ter um parto normal. Ela dizia: pra quê que eu vou passar por isso? Eu não sou índia! Eu vou lá, faço uma cesárea e pronto. Tive que ter muita força pra bancar o que eu queria" (PV pós-PC; setor privado).

"A maioria das minhas amigas teve cesárea, mas todas elas queriam um parto normal, não eram satisfeitas com o parto que fizeram. Eu fico revoltada quando uma pessoa diz que fez cesárea porque o médico se precipitou ou porque inventou uma desculpa esfarrapada" (PC pós-PV; setor privado).

Entre as informantes do setor público, nenhuma evidência de uma "cultura da cesárea" 8 foi constatada. Ao contrário, a influência do seu grupo social pelo parto normal, as dificuldades da recuperação da cesárea e a representação de que este procedimento cirúrgico retira da mulher o prazer em colocar o filho no mundo, apesar do manejo inadequado das dores do parto nas maternidades públicas, como veremos adiante, configuram um quadro de majoritária preferência pelo parto normal.

As diferenças de concepção da cesárea apontam para uma maior aceitação social da cesárea entre mulheres das camadas médias. Nesse grupo, o desejo pela cesárea atual foi decorrente da opção pela laqueadura. A construção social da "normalidade" da cesárea nesse grupo parece refletir o fato de ser, crescentemente, uma via de parto possível e usual - em parte por ser via de acesso à laqueadura. 
Dor no trabalho de parto, sexualidade e qualidade da assistência

Alguns estudos sobre a assistência ao parto, citados anteriormente, destacam a importante influência das dores do parto e seu manejo, bem como de outras representações sobre o corpo e a sexualidade na conformação das preferências e experiências femininas no nascimento. Nessa direção, aprofundamos o sentido dessas representações e o tipo de influência sobre o processo de parto, à luz das construções de gênero.

As representações e vivências quanto às dores do parto normal foram muito semelhantes, independente de terem sido atendidas em serviços públicos ou privados. Referem dores intensas, mas próprias a esse tipo de parto. A naturalização das dores do parto normal como um aspecto intrínseco do ato de parir, fez com que na comparação com a cesárea, ainda assim preferissem as dores do parto normal, pois na cesárea as dores também estarão presentes, excluindo as vivências e sensações de protagonizar o nascimento do filho. Esse é o principal diferencial quanto às dores do parto: elas são inevitáveis e surgirão durante o trabalho de parto normal e, portanto, mais intensas e sofridas, ou após a cesariana, no puerpério imediato.

"É inevitável. Se a gente não sentir dor, como é que a gente vai botar os filhos pra fora? É a dor de mãe que a gente tem sentir mesmo" (PC pós-PV; setor público).

A preferência pelas dores do parto normal é exatamente a sensação de que esta é a "dor de mãe", aquela em que se está consciente de que é intrínseca e necessária para se ter o bebê. O protagonismo feminino ao passar pelas contrações, fazer força e sentir o bebê nascer, mesmo que em algumas vezes a dor seja sentida como insuportável, supera a vivência da cesárea, na qual não existe este protagonismo e o prazer a ele associado. Na cesárea, as dores virão necessariamente após o parto. A dor de parto foi considerada um componente natural e essencial da maternidade. Embora ela represente sofrimento, as mulheres aceitam experimentá-la e sentem-se capazes de tolerá-la. Isso demonstra que a interpretação da dor não se faz apenas com base em sensações fisiológicas, mas fundamentalmente a partir do seu significado no processo de nascimento.

No entanto, a percepção da intensidade da dor variou entre os dois grupos sociais, e o principal aspecto que as diferencia é o tipo de assistência ofertado para o manejo da dor. As entrevistadas do setor privado têm o parto monitorado e com analgesia. As mulheres do setor público, além de não terem disponível o uso dessa tecnologia médica, ainda vêem aumentada a sua dor pelo uso indiscriminado e rotineiro da ocitocina e também pelo medo de maus-tratos por parte dos profissionais de saúde, caso se "descontrolem" devido à intensidade das contrações. Essas informantes têm uma pior percepção quanto às dores do parto e clareza que o tipo de assistência que recebem agrava e não diminui as dores. Essas mulheres dizem que tentam se controlar, "tirar forças de Deus", "não fazer escândalo".

Sobre a relação existente entre tipos de parto e sexualidade, a maioria das informantes que tiveram PC pós-PV considerou que há diferenças entre parto normal e cesárea para o retorno às atividades sexuais. Opinaram que os pontos, a demora na cicatrização e os maiores cuidados para a recuperação da cesárea são fatores que retardam o reinício da atividade sexual, em comparação com o parto normal. A maioria das mulheres que tiveram PV pós-PC não percebeu diferenças entre os tipos de parto e o reinício da atividade sexual.

Alguns estudos afirmam que existiria uma idéia corrente de que as mulheres prefeririam uma cesárea porque o parto normal deixaria a vagina larga, mas todas as entrevistadas refutaram este mito. Grande parte disse que parece que ficaram "virgens" novamente por causa dos pontos que levaram no períneo. Como esse procedimento médico é recorrente e, segundo Diniz 6, tem sido utilizado como um tipo de "cirurgia sexual”, não há evidência da idéia do parto normal interferindo na sexualidade feminina.

\section{Experiências femininas sobre a assistência ao parto}

Uma das principais motivações desta investigação foi tomar como objeto central da análise as experiências de mulheres de grupos sócio-econômicos distintos e com acesso diferenciado à assistência ao parto, para entender como as variações relacionadas com a prática médica e a organização dos serviços podem contribuir para a manutenção de altas taxas de cesárea e de outras intervenções no parto, bem como favorecer ou dificultar o exercício dos direitos sexuais e reprodutivos. Nesse sentido, não se pode deixar de levar em conta como, no contexto dos serviços, instituíram-se as relações entre profissionais de saúde e usuárias, bem como a própria compreensão das mulheres como detentoras de direitos sexuais e reprodutivos.

No que se refere às orientações recebidas no pré-natal sobre o parto, a maior parte das entrevistadas não se sentiu adequadamente preparada. Segundo elas, as informações necessárias sobre o parto - tipos de parto, reconhecimento dos sinais do início do trabalho de parto, evolução 
e procedimentos utilizados no parto, possíveis intercorrências que possam levar a uma cesárea, suas indicações e riscos - para que a mulher possa vivenciá-lo com segurança, participação e autonomia não foram prestadas e trabalhadas de forma apropriada no pré-natal.

Os principais motivos destacados pelas mulheres para essa insuficiente preparação para o parto foram: mulheres com intercorrências na gestação apenas eram orientadas sobre a possibilidade da cesárea e em gestantes com maior paridade e com expectativa de parto normal, os médicos não abordaram essa temática. Constata-se, então, que o processo educativo na atenção pré-natal não vem sendo ampla e eficazmente utilizado. Esse desconhecimento feminino sobre os seus processos corporais - elemento que perpassa os grupos pesquisados - contribui para que as mulheres tenham dificuldades em protagonizar seus eventos corporais e tomar decisões e escolhas conscientes sobre eles.

Quando perguntadas sobre a qualidade do cuidado da equipe de saúde durante o parto, a maioria das entrevistadas o considerou muito bom. Para aquelas que tiveram um PC pós$\mathrm{PV}$, nos dois setores estudados, destacaram um maior cuidado no que se refere às suas condições clínicas, principalmente por serem partos de alto risco.

Entre as que tiveram PV pós-PC a percepção foi semelhante pela atenção prestada na tentativa de trabalho de parto vaginal após uma cesariana. Algumas informantes, em ambos os grupos, relataram vivências de abandono, frieza e excesso de intervenções nos partos anteriores, o que as fez avaliar positivamente a presente experiência.

As entrevistadas do setor privado destacaram como elemento fundamental para a qualidade do cuidado médico recebido a relação de proximidade e confiança construída ao longo do tempo. Entre aquelas do setor público, o principal aspecto foi o trato respeitoso e a não experimentação de situações de maus-tratos.

Ao serem indagadas sobre como acham que o médico deve tratar as mulheres durante o parto, todas do setor público reforçaram a importância de um tratamento digno, respeitoso, acolhedor e sintonizado com as suas necessidades. Ouvir o que elas têm a dizer, ter paciência com as suas dores, passar tranqüilidade informando-as do que está acontecendo e explicando o que deve ser e está sendo feito são demandas importantes dessas mulheres frente às experiências de violência institucional, como piadas, discriminações e intolerância. As mulheres do setor privado destacaram a mesma necessidade de orientação, apoio, atenção e segurança. Percebem que um tratamento respeitoso e acolhedor pode favore- cer o parto, e que o contrário pode tencionar a mulher e dificultar todo o processo.

Interessante notar que as entrevistadas consideraram que os aspectos clínicos e a utilização de tecnologias no trabalho de parto e parto são menos importantes do que a forma como são tratadas e o processo do parto é conduzido. $\mathrm{O}$ que essas informantes destacam como necessidades de saúde na assistência ao parto revela necessidades direcionadas à procura de um vínculo com o profissional de saúde - vínculo enquanto referência e relação de confiança - e que favoreça, ao mesmo tempo, a obtenção de graus crescentes de autonomia, implicando a reconstrução dos sentidos do seu corpo e da experiência do nascimento.

No tocante ao conhecimento sobre a sua situação e a do bebê antes e durante o parto, as percepções se dividiram. A maioria das informantes do setor público se ressentiu da falta de informação no que dizia respeito à condição clínica do bebê e/ou ao entendimento do diagnóstico que levou à cesárea. Sinalizaram que a equipe faz os procedimentos médicos necessários, mas não informam ou compartilham os seus resultados. No setor privado, todas disseram que sabiam como estavam os bebês por meio dos mais variados exames, e que o médico informava sobre os procedimentos, resultados e decisões clínicas. Especificamente, entre as que tiveram PV pósPC, todas tiveram os seus partos monitorados, o que determinou maior troca de informações entre médico e paciente.

Todas as mulheres que tiveram uma cesárea no parto anterior sabiam os motivos da indicação da cesárea, porém, a maioria ficou com muitas dúvidas sobre a sua necessidade. Observamos entre as entrevistadas do setor privado iniciativas de procurar um médico que fizesse um parto normal após essa cesárea, já que questionavam a sua indicação. Em decorrência desse contexto de dúvida ou discordância, perguntamos às mulheres como enfrentaram essa situação. A maioria aceitou a indicação pelo desconhecimento aliado à confiança no médico. Porém, essa confiança não se caracterizou por uma relação baseada no diálogo, na troca de opiniões e dúvidas, no ouvir e acolher as necessidades das usuárias, mas por meio de uma relação hierárquica de poder em que a mulher encontra-se no lugar do não-saber e o médico no lugar que representa o "deixa tudo por minha conta que eu sei o que estou fazendo": "Na época, concordei porque tinha pouca experiência sobre o parto. Hoje, com a minha experiência, teria uma atitude mais ativa diante do médico, não me entregaria totalmente. Ele me assustou e eu fiquei refém da decisão dele. É aquela coisa, eu tive que concordar, porque ou você confia ou 
muda de médico, tanto é que agora eu mudei" (PV pós-PC; setor privado).

Esses resultados se equiparam àqueles encontrados por LoCicero ${ }^{9}$, nos Estados Unidos. A autora destaca que nessa relação as mulheres ficam sem a fala, o que pode gerar divergências. Esses conflitos, então, vão aparecer depois do momento do parto. Freqüentemente, as expectativas e crenças que as mulheres possuem antes do parto são significativamente comprometidas pelo processo de nascimento. Muitas mulheres que chegaram ao hospital achando que tudo iria correr bem, o deixaram achando que seus corpos falharam, e um outro número delas considerou que a assistência que tiveram foi inadequada. Várias mulheres concluíram que seus obstetras foram insensíveis, desrespeitosos e ansiosos para abreviarem o processo de nascimento.

Mas, as explicações da equipe de saúde traziam segurança para as parturientes? Aqui, novamente as respostas se dividem. Entre as usuárias do setor público, a precariedade das informações as deixavam inseguras, principalmente aquelas que fizeram PC pós-PV, porque tiveram cesarianas decididas durante o trabalho de parto. No setor privado, todas disseram que se sentiram seguras com as informações que lhes eram prestadas, bem como que a equipe as tranqüilizava a todo momento. Mais uma vez, um aspecto importante que contribuía para essa segurança foi o fato de terem feito o pré-natal e o parto com o mesmo obstetra.

Quando indagadas se tinham espaço para perguntar o que o médico fazia com elas e liberdade para opinar e decidir sobre seus processos corporais no parto, verificamos que as mulheres do setor privado sentiam-se mais à vontade para questionar o médico sobre determinados procedimentos do que as mulheres do setor público. Entretanto, elas se igualam na atitude pouco ativa frente ao processo do parto. Verificamos que a maior parte dos médicos informa mas não pergunta o que elas desejam ou preferem em relação ao que vai ser feito durante o parto, seja ele normal ou cesárea. As mulheres, por seu turno, preferem não opinar e nem decidir já que transferem essas decisões para a equipe de saúde. No caso das mulheres do setor privado, tanto a relação de confiança como a hierarquia estabelecida servem de salvo-conduto para as ações médicas, apesar de terem espaço para perguntar e opinar. Por outro lado, também tivemos relatos de mulheres que não ficaram satisfeitas com a cesárea anterior e procuraram outro médico para assistilas no parto atual.

As mulheres do setor público não se sentem à vontade ou têm receio em questionar ou opinar sobre a conduta da equipe de saúde. Dife- rentemente do outro grupo, em poucos casos se construiu uma relação de proximidade e confiança que favorecesse um canal de expressão para questionamentos e decisões, delegando-se ao médico a responsabilidade com a adequada assistência, "porque eles sabem o que tem que fazer". Semelhantemente às mulheres do setor privado, pouco opinavam ou decidiam sobre o parto, pois não percebiam um terreno propício para a colocação de opiniões e espaço para a tomada de decisão.

Apesar dessas diferenças, alguns aspectos fundamentais as iguala: a falta de conhecimento sobre o processo do parto, sua fisiologia, principais procedimentos, indicações de cesárea e outros. Sem o conhecimento dos processos corporais inerentes ao parto, as mulheres ficam subordinadas à condução médica. Seja por meio do lastro da "confiança" entre as informantes do setor privado, seja pela falta de reconhecimento da sua cidadania entre as mulheres do setor público, todas se aproximam na precariedade de conhecimento sobre os seus processos corporais, configurando a submissão ao processo de medicalização, mesmo que este se manifeste de forma diferenciada entre mulheres de distintos estratos sócio-econômicos.

Entretanto, é importante realçar que a crítica ao excesso de utilização de tecnologias médicas é, hoje, uma bandeira político-ideológica perigosamente útil às tendências pragmáticas de redução dos gastos em saúde pública, uma vez que na gravidez, parto e puerpério de amplos setores da população não são utilizados os recursos tecnológicos necessários ou o são deficientemente. De outro lado, contraditoriamente, as taxas de cesárea são muito mais elevadas no setor privado, no qual em função do menor risco materno e da maior disponibilidade de recursos tecnológicos de monitoramento do parto poder-se-ia esperar menores índices desse procedimento.

Na perspectiva das taxas de cesárea, a medicalização do corpo feminino parece ser maior no setor privado. Porém, mediando esse processo está o desejo feminino da esterilização, o que as leva a optarem pela cesárea, mesmo não sendo o momento nem a via melhor para esse procedimento. A relação mais estreita com os médicos pode também significar maior socialização para a medicalização, tal como refere o trabalho de Silver 10 .

Podemos inferir, então, que a utilização de tecnologia médica - como uma expressão do processo de medicalização do corpo feminino - manifesta-se de forma diferenciada, segundo o perfil sócio-econômico da clientela e dos contornos que a prática médica toma com base no modelo de organização da assistência. 
Reafirmamos que essa discussão não pode estar desvinculada da assistência. O cenário do nascimento transformou-se, tornando-se desconhecido e amedrontador para as mulheres e mais conveniente e asséptico para os profissionais de saúde. É preciso aqui voltar a uma questão muito debatida: quem é o protagonista da cena do parto? A mulher-parturiente parece estar cada vez mais distante dessa condição: mal-informada e insegura submete-se a todas as ordens ou orientações, sem entender como combinar o poder contido nas atitudes e palavras que ouve e percebe com o fato inexorável de que é ela quem está com dor e quem vai parir. Em uma relação assimétrica profissional de saúde/usuária e dependente dos médicos para se informarem, as mulheres têm dificuldade em participar das decisões relativas ao seu parto, sentindo-se menos capacitadas para escolher e fazer valer seus desejos frente às "questões técnicas" levantadas pelos médicos.

Dessa forma, a eficácia técnica do saber médico constitui o pano de fundo no qual o "critério médico", como discurso justificador e normatizador dos comportamentos reprodutivos, adquire uma contundência real difícil de ser enfrentada pela maioria das mulheres 11 . O peso das decisões na obstetrícia, mesmo tendo como resultado uma negociação surda com outros saberes, inclusive os das próprias mulheres e onde a patologia é exceção, legitima-se na técnica, na responsabilidade e experiência médica capaz de justificar sua autoridade. Nesse sentido, o peso das decisões na assistência ao parto não pode recair sobre as mulheres, mas fundamentalmente é a prática médica e a forma como a assistência está organizada nos setores público e privado que necessitam mudar. A atuação educativa de grupos organizados de mulheres e profissionais responsáveis poderia potencializar as mulheres como sujeitos da sua saúde, influenciando positivamente na relação médico/parturiente.

\section{Considerações finais}

A pesquisa desenvolvida confirma os resultados de outras análises 12 que apontam para a preferência feminina pelo parto normal como uma vivência de protagonismo e de maior satisfação na cena do parto.

Os modelos de organização dos serviços público e privado apresentam variações que produzem diferentes tipos de assistência e de relação entre os profissionais de saúde e usuárias, dando forma a experiências distintas entre as mulheres pesquisadas. As diferenças em torno do manejo da dor no trabalho de parto, a relação de continuidade entre pré-natal e parto e a confiança estabelecida entre médicos e pacientes do setor privado foram atributos importantes destacados pelas mulheres.

Todavia, ao buscarmos compreender como ilustrativos de uma ótica de gênero na atenção ao parto aspectos como maior conhecimento e apropriação por parte das mulheres de seus processos corporais e possibilidade de escolha na assistência em saúde, verificamos que faltam a todas elas as informações fundamentais para que vivenciem com segurança e autodeterminação o parto. Apesar das diferenças evidenciadas, a maior parte das mulheres dos dois grupos sociais não tem conhecimento sobre as informações que deveriam receber no parto, vivenciam relações assimétricas com os profissionais de saúde e não apresentam condições para tomar decisões autônomas. Além disso, a cultura do risco obstétrico e do medo do parto normal, evidenciada com diferentes nuances conforme o vínculo com o profissional e a instituição, gera grandes dificuldades para aquelas mulheres que desejam contorná-la. Os resultados mostram as contradições existentes na relação profissional de saúde/usuárias, mediadas pelas questões de gênero presentes na assistência ao parto e pela natureza dos serviços. As mulheres apresentam algumas críticas ao que fazem ou fizeram com elas. No entanto, fica evidente a pouca margem de manobra que possuem dado o caráter da atenção ofertada. Apesar dos aspectos em comum, traços específicos as diferenciam e precisam ser conhecidos para que possam ser traçadas estratégias direcionadas a cada perfil de organização de serviços.

Podemos afirmar que a assistência ao parto permanece submetendo quem deve ser sujeito e reproduzindo o projeto da medicalização - mesmo que este processo se manifeste de formas diferenciadas entre os grupos estudados -, o que reduz o campo da assistência e inviabiliza um lugar de poder diferenciado das usuárias, bem como sua conscientização, autonomia e exercício de seus direitos em saúde. 


\section{Resumo}

Este estudo analisa as diferentes representações e experiências quanto ao parto vaginal e cesárea de mulheres de diferentes estratos sócio-econômicos, bem como a natureza das relações profissionais de saúdel usuárias no contexto institucional em que estão inseridas. A pesquisa de natureza qualitativa foi desenvolvida em três maternidades do Município do Rio de Janeiro, Brasil, sendo uma pública, uma conveniada com o SUS e uma particular, com mulheres que tiveram os dois tipos de parto. Os resultados revelam que o modelo de organização dos serviços público e privado apresentam variações que produzem diferentes tipos de assistência e de relação entre os profissionais de saúde e as usuárias, dando forma a experiências distintas entre as mulheres pesquisadas. Todavia, ao empreendermos uma crítica assentada nas relações de gênero, podemos verificar que o modelo de assistência ao parto permanece submetendo quem deve ser sujeito e reproduzindo o projeto da medicalização - mesmo que este processo se manifeste de formas diferenciadas entre os grupos estudados -, o que reduz o campo da assistência e inviabiliza um lugar de poder diferenciado das usuárias.

Serviços de Saúde Materno-Infantil; Parto Normal; Cesárea

\section{Colaboradores}

A. S. Gama participou do planejamento, coleta e análise dos dados da pesquisa e elaboração do artigo. K. M. Giffin coordenou a pesquisa, participou do planejamento e da elaboração do artigo. A. Angulo-Tuesta participou do planejamento, coleta e análise dos dados da pesquisa e da revisão da versão final do artigo. E. d'Orsi e G. P. Barbosa participaram do planejamento, análise dos dados da pesquisa e da revisão da versão final do artigo.

\section{Agradecimentos}

Agradecemos à Fundação Ford e ao Conselho Nacional de Desenvolvimento Científico e Tecnológico (CNPq) o apoio dado à pesquisa.

\section{Referências}

1. Departamento de Análise de Situação em Saúde Secretaria de Vigilância em Saúde, Ministério da Saúde. Brasil: uma análise da situação de saúde. http://portal.saude.gov.br/portal/arquivos/pdf/ saude_brasil_2005.pdf (acessado em 10/Jan/2008).

2. Angulo-Tuesta A, Giffin K, Gama AS, d'Orsi E, Barbosa GP. Saberes e práticas de enfermeiros e obstetras: cooperação e conflitos na assistência ao parto. Cad Saúde Pública 2003; 19:1425-36.

3. Departamento de Análise de Situação em Saúde Secretaria de Vigilância em Saúde, Ministério da Saúde. Saúde Brasil 2006: uma análise da desigualdade em saúde. http://portal.saude.gov.br/portal/ arquivos/pdf/saude_brasil_2006.pdf (acessado em $10 / \operatorname{Jan} / 2008$ )

4. Giffin K. Pobreza, desigualdade e eqüidade em saúde: considerações a partir de uma perspectiva de gênero transversal. Cad Saúde Pública 2002; 18 Suppl:103-12.

5. Gama AS. Gênero e avaliação da qualidade da atenção em serviços de saúde reprodutiva. In: Bravo MIS, Vasconcelos AM, Gama AS, Monnerat GL, organizadoras. Saúde e serviço social. São Paulo: Cortez Editora/Rio de Janeiro: Universidade do Estado do Rio de Janeiro; 2004. p. 79-96.

6. Diniz CSG. Entre a técnica e os direitos humanos: possibilidades e limites da humanização da assistência ao parto [Tese de Doutorado]. São Paulo: Faculdade de Medicina, Universidade de São Paulo; 2001 .

7. Kitzinger S. A experiência de dar à luz. São Paulo: Editora Martins Fontes; 1987.

8. Faúndes A, Cecatti JG. A operação cesárea no Brasil: incidência, tendências, causas, conseqüências e propostas de ação. Cad Saúde Pública 1991; 7:150-73.

9. LoCicero AK. Explaining excessive rates of cesarean and other childbirth interventions: contribution from contemporany theories of gender and psychology development. Soc Sci Med 1993; 37:1261-6.

10. Silver L. Direito à saúde ou medicalização da mulher? In: Giffin K, Costa SH, organizadores. Questões da saúde reprodutiva. Rio de Janeiro: Editora Fiocruz; 1999. p. 299-317.

11. Grassi E, Raggio L, Montes AG. Normatização dos comportamentos reprodutivos e paradigmas médicos: estudo de caso em instituições de saúde para camadas médias. In: Costa AO, Amado T, organizadores. Alternativas escassas: saúde, sexualidade e reprodução na América Latina. São Paulo: Fundação Carlos Chagas/Rio de Janeiro: Editora 34; 1994. p. 205-48.

12. Barbosa GP, Giffin K, Angulo-Tuesta A, Gama AS, Chor D, d'Orsi E, et al. Parto cesáreo: quem o deseja? Em quais circunstâncias? Cad Saúde Pública 2003; 19:1611-20.

Recebido em 06/Jun/2008

Versão final reapresentada em 07/Jul/2009 Aprovado em 01/Set/2009 